IJ§ER

ISSN: 2149-5939
International Journal of Social Sciences and Education Research

Online, http://dergipark.gov.tr/ijsser

Volume: 3(1), 2017

\title{
Etkinlik kavramının öğretmen adaylarının bakış açısıyla farklı bo- yutlarda incelenmesi
}

\section{Investigation of the concept of activity in different dimensions according to the perspective of pre-service teachers}

\section{Gönül Kurt Erhan ${ }^{1}$}

Received Date: 11 / 09 / 2016

\author{
Özge Yiğitcan Nayir ${ }^{2}$
}

Accepted Date: 25 / 12 / 2016

$\ddot{O} z$

Matematik öğretim programlarında sıklıkla bahsedilen ve yapılandırmacı yaklaşımın en önemli unsurlarından olan etkinlik kavramına dair öğretmen ve ögretmen adaylarının görüşleri araştırılmış ve çok çeşitli tanımlamalar yapılmıştır. Matematik ögretimine dair çăgdaş yönelimlerle özdeşleşmiş olan etkinlik kavramının genel bir çerçevede tanımlanması, özelliklerinin belirlenmesi, ögrenci ve öğretmen rollerinin netleşmesi, sını içi uygulamaların etkililiği ve anlamlılığı bakımından önemli görülmektedir. Bu çalışmada, hizmet içi eğitimleri öncesi, sınıf öğretmeni ve ilköğretim matematik ögretmen adaylarının etkinlik kavramına yönelik algılarını incelemek, bir etkinlikte olması gereken özelliklerle birlikte öğrenci ve ögretmen rollerini belirlemek amaçlanmıştır. Çalışma grubu, bir vakıf üniversitesinin ilköğretim bölümü sını öğretmenliği ve matematik öğretmenliği programı 3. ve 4. sinıflarında ögrenim gören toplam 68 ögretmen adayından oluşmaktadır. Öğretmen adaylarına, matematik öğretimi göz önünde bulundurularak "etkinlik deyince aklıma gelen ilk şey..." cümlesini doldurmalart istenmiştir. Öğretmen adaylarının yanıtlarının 'amaç, 'nitelik' ve 'isimlendirme' olarak üç kategoride toplandığı ve oldukça çeşitlilik gösterdiği görülmüsstür. Buna ek olarak, ögretmen adaylarının etkinliği nasıl tanımladıkları, etkinliği oluşturan unsurların neler olduğu, öğrenci-öğretmen rollerinin neler olması gerektiğine dair sorulan sorularla öğretmen adaylarının etkinlik kavramına ilişkin algıları araştırılmıştır.

Anahtar Sözcükler: Etkinlik, matematik ögrretimi, öğretmen adayı

\begin{abstract}
Activity is one of the important components of constructivist approach and commonly referred in the elementary mathematics curriculum. In the literature, teachers' and pre-service teachers' views about activity were investigated and various definitions were suggested. It is important to define the concept of activity identified with the contemporary approaches of mathematics teaching, to determine its features, to clarify the roles of students and teachers and the effectiveness of in-class activities. In this study, it is aimed to examine the perceptions of preservice primary and elementary mathematics teachers, before their in-service education, regarding the concept of activity as well as identifying the features should be included in an activity and roles of both students and teachers. The study group consists of 68 junior and senior pre-service teachers attending the primary education and elementary mathematics education programs of a private foundation university. The pre-service teachers were asked to fill the sentence "the first thing in my mind when the term of activity is considered is ..." regarding mathematics teaching. It was seen that the responses of pre-service teachers vary considerably and gathered into three categories, namely as aim, qualification, and labelling. Further, it was investigated how pre-service teachers define the concept of activity with the questions to determine the components of activity and roles of students and teachers in an activity with an interview form. The responses of pre-service teachers were analysed by qualitative methods and the codes and the categories were presented in the tables.
\end{abstract}

Keywords: Activity, mathematics teaching, pre-service teachers

${ }^{1}$ gonulkurt@gmail.com

${ }^{2}$ Başkent Üniversitesi, Ankara, Türkiye, yigitcan@baskent.edu.tr 
Kurt Erhan, G., Yiğitcan Nayir, Ö. (2017). Etkinlik kavramının öğretmen adaylarının bakış açısıyla farklı boyutlarda incelenmesi. International Journal of Social Sciences and Education Research, 3(1), 283-296.

\section{Giriş}

Öğrenmenin gerçekleşmesi için öğrencilerin araştırma ve sorgulama yapabilecekleri, iletişim kurabilecekleri, eleştirel düşünebilecekleri, fikirlerini rahatlıkla paylaşabilecekleri açık uçlu soru ve etkinliklere yer verilen öğrenme ortamlarının sağlanmasının gerekliliği bilinmektedir. Matematik öğreniminin de temelinde öğrencilerin matematiksel fikirler edineceği, akıl yürütme ve ilişkilendirme yaparak problemlere çözüm üretebileceği yapılandırmacı bir öğrenme ortamı fırsatı sunulmalıdır. Yapılandırmacı yaklaşımın önemli bir unsuru olarak ve matematik öğretim programlarında sıklıkla bahsedilen etkinlik kavramına dair farklı tanımlamalar yapılmıştır. Türk Dil Kurumunun güncel Türkçe sözlügünde "etkin olma durumu" şeklinde tanımlanan etkinlik kavramı, Bilim ve Sanat Terimleri Ana Sözlüğünde "çocukların, kendi amaç ve gereksinmelerine uygun geldiği için isteyerek katıldıkları herhangi bir öğrenme durumu" şeklinde tanımlanmıştır (TDK, 2016). Bu tanımlara ek olarak, ilgili alan yazında etkinlik kavramının öğretmen adayları ve/veya öğretmenler tarafından nasıl tanımlandığına dair çalışmalar yürütülmüştür. Bozkurt (2012) etkinlik kavramını, matematik öğretimi özelinde, "herhangi bir matematiksel kazanıma yönelik gerçekleştirilmesi mümkün olan bir görevin, öğrencilere sorumluluklar verilerek ve birtakım araç-gereçler kullanılarak, uygulamaya geçirilmesi sonucu belirli bir ürün ortaya koymaktır" (s. 104) şeklinde tanımlamıştır. Uğurel ve Bukova-Güzel (2010) de "birey ile çevre arasındaki etkileşim ile (istekli olarak) girişilen bir öğrenme ya da çalışma eylemi olarak görülebilir" (s. 334) ifadesiyle etkinliği tanımlamışlardır.

Etkinlik kavramının öğrenci, öğretmen ve öğretmen adayı tarafından nasıl tanımlandığı/alg1landığı konusunda yapılan çalışmalar, tanımların çeşitliliğinin çok fazla olduğunu, bu konuda ortak bir görüşe ulaşılamadığını göstermektedir (Bozkurt, 2012).

Kösterelioğlu, Bayar ve Akın Kösterelioğlu'nun (2014) yürüttüğü araştırmada, bir devlet üniversitesinin eğitim fakültesi Türkçe Öğretmenliği ve Fen Bilgisi Öğretmenliği bölümlerinde öğrenim gören toplam 40 öğretmen adayının etkinlik temelli öğrenme sürecine ilişkin görüşleri araştırılmıştır. Araştırmanın bulguları, öğretmen adaylarının etkinlik temelli öğrenmenin öğrenenin aktif katılımını desteklediği, kalıcı ögrenmeye firsat verdiği, öğrenmeyi kolaylaştıran ve keyifli hale getiren bir uygulama olduğuna dair görüşlerini ortaya çıkarmıştır.

İlgili alan yazında, etkinlik temelli öğretimin akademik başarıya, tutuma etkisinin araştırıldığ çalışmalar yer almaktadır. (Batdı, 2014; Gürbüz, 2010; Küpcü, 2012; Uşun ve Gökçen, 2010). Batdı'nın (2014) yürüttüğü meta-analitik çalışmada, 2006-2014 yılları arasında etkinlik temelli öğretimin akademik başarıya etkisini konu edinen beş adet bilimsel araştırma incelenmiştir. Araştırmanın bulguları, etkinlik temelli öğretimin akademik başarıya yüksek düzeyde etki ettiğini göstermektedir. Klasik yöntemle işlenilen derslere kıyasla, etkinlik yapılan derslerde, öğrencilerin konuları daha iyi anladığı, dersleri daha çok sevdiği ve öğrenmenin kalıcı olduğu sonuçları belirtilmiştir.

Etkinlik kavramının yer aldığı bir başka çalışmada Kösterelioğlu ve Yapıcı (2016), etkinlik temelli öğrenme sürecinin öğretmen adaylarının yapılandırmacı öğrenme ortamı algılarına etkisini araştırmıştır. Bu araştırma sonuçları, 3. ve 4. sınıflarda öğrenim gören Türkçe, Matematik ve Fen Bilgisi öğretmen adaylarının algılarında olumlu etki yaptığı ve etkinliklerle desteklenen öğrenme-öğretme sürecinde, öğrenenlerin aktif katılımının öğrenmeleri üzerinde de olumlu etkilerinin olduğu belirtilmiştir. 
Kurt Erhan, G., Yiğitcan Nayir, Ö. (2017). Investigation of the concept of activity in different dimensions according to the perspective of pre-service teachers. International Journal of Social Sciences and Education Research, 3(1), 283-296.

\section{Amaç}

Öğrencilerin kalıcı ve anlamlı öğrenmelerini sağlamak üzere etkinlik temelli bir öğrenme öğretme ortamının oluşturulması, yapılandırmacı öğrenme yaklaşımının temel prensiplerinden biridir. $\mathrm{Bu}$ amaçla uygun ve nitelikli etkinliklerin ortaya konulabilmesinin etkinlik kavramının nasıl algılandığı ile doğrudan ilişkili olduğu düşünülmektedir (Uğurel ve Bukova-Güzel, 2010). Bununla birlikte, matematik eğitimcilerinin yer aldığı özellikle ulusal katılımlı bilimsel toplantılarda sunulan ve etkinlik olarak tanımlanan çalışma ve uygulamaların etkinlik kavramıyla ne derece örtüştüğü konusunun sıkça tartışıldığı gözlemine dayanarak, etkinliğin nasıl tanımlandığı, nasıl algılandığı sorusu ele alınmış ve bu çalışmanın çıkış noktası oluşturulmuştur. Matematik öğretimine dair çağdaş yönelimlerle özdeşleşmiş olan etkinlik kavramının genel bir çerçevede tanımlanması, unsurlarının ve özelliklerinin belirlenmesi, öğrenci ve öğretmen rollerinin netleşmesi sınıf içi uygulamaların etkililiği ve anlamlılığı bakımından önemli görülmektedir. Bu çalışmada, hizmet içi eğitimleri öncesi, sınıf öğretmeni ve ilköğretim matematik öğretmen adaylarının etkinlik kavramına yönelik algılarını incelemek, bir etkinlikte olması gereken özelliklerle birlikte öğrenci ve öğretmen rollerini belirlemek amaçlanmıştır.

\section{Yöntem}

Bu çalışmada nitel araştırma türlerinden olgu bilim deseni kullanılmıştır. Yaşantılara dair deneyimler, algılar, yönelimler, kavramlar gibi çeşitli durumlar olgular olarak adlandırılabilir. Olgu bilim deseninde araştırmaya dahil olan katılımcıların kişisel (öznel) tecrübeleri, algılamaları ve olaylara yükledikleri anlamlar incelenmektedir (Baş ve Akturan, 2008). Bu çalışmanın odağını da etkinlik kavramının sınıf ve matematik öğretmen adayları için ne anlama geldiği ve bu kavramı nasıl algıladıkları oluşturmaktadır.

\section{1. Çalışma grubu}

2015-2016 öğretim yılı bahar döneminde bir vakıf üniversitesinin ilköğretim bölümü sınıf öğretmenliği programı 3. ve 4. sinıflarında öğrenim gören 47 ve matematik öğretmenliği programı 3. ve 4. sınıflarında öğrenim gören 21 öğretmen adayı olmak üzere toplam 68 öğretmen adayı çalışma grubunu oluşturmaktadır. Çalışma grubunun belirlenmesinde matematik öğretimi derslerini almış veya dönem itibariyle alıyor olmak ölçüt olarak belirlenmiştir. Tablo 1'de görüldüğü üzere, çalışmaya katılan öğretmen adaylarının \% 69'u Sınıf Öğretmenliği programında, \% 31'i ise Matematik Öğretmenliği programındadır. Bölümlere ve sınıf düzeylerine göre öğretmen adaylarının sayıları Tablo 1'de görülmektedir.

Tablo 1. Bölümlere ve sınıf düzeylerine göre öğretmen adaylarının sayıları

\begin{tabular}{|c|c|c|c|c|c|c|}
\hline & \multicolumn{4}{|c|}{ Sınıf Düzeyi } & & \\
\hline & \multicolumn{2}{|c|}{ 3. Sinıf } & \multicolumn{2}{|c|}{ 4. Sinıf } & \multicolumn{2}{|c|}{ Toplam } \\
\hline & $\mathrm{N}$ & $\%$ & $\mathrm{~N}$ & $\%$ & $\mathrm{~N}$ & $\%$ \\
\hline Sınıf Öğretmenliği (S.Ö.) & 18 & 72 & 29 & 67 & 47 & 69 \\
\hline $\begin{array}{l}\text { Matematik Öğretmenliği } \\
\text { (M.Ö.) }\end{array}$ & 7 & 28 & 14 & 33 & 21 & 31 \\
\hline Toplam & 25 & 100 & 43 & 100 & 68 & 100 \\
\hline
\end{tabular}


Kurt Erhan, G., Yiğitcan Nayir, Ö. (2017). Etkinlik kavramının öğretmen adaylarının bakış açısıyla farklı boyutlarda incelenmesi. International Journal of Social Sciences and Education Research, 3(1), 283-296.

\subsection{Veri toplama araçları}

Öğretmen adaylarından, matematik öğretimi göz önünde bulundurularak "etkinlik deyince aklıma gelen ilk şey..." cümlesinin yazılı olduğu formu doldurmaları istenmiştir. Öğretmen adayları yanıtlarını sınıf ortamında herhangi bir yönlendirme (kelime veya cümle sayısı sınırlandırılması gibi) yapılmadan vermişlerdir. Bu formun doldurulmasından sonra, aşağıdaki soruların bulunduğu bir başka form verilmiş ve yanıtların yazılı olarak verilmesi istenmiştir.

1. Etkinliği nasıl tanımlarsınız?

2. Sizce, etkinliği oluşturan unsurlar nelerdir?

3. Sizce etkinliklerde öğrencinin rolü ne olmalıdır?

4. Sizce etkinliklerde öğretmenin rolü ne olmalıdır?

5. Sizce iyi bir etkinlikte bulunması gereken özellikler nelerdir?

\subsection{Verilerin analizi}

68 öğretmen adayının formlardaki sorulara verdiği yanıtlar çalışmayı yürüten iki araştırmacı tarafından içerik analizi yöntemi ile analiz edilmiştir. Araştırmacılar öncelikle ayrı ayrı verileri analiz etmiş, daha sonra bir araya gelerek ortak bir kanıyla araştırmanın amacı yönünde analizleri tamamlamışlardır. Ortaya çıkan kodlar bir araya getirilerek kategoriler belirlenmiştir.

\section{Bulgular ve tartışma}

Bu bölümde, öğretmen adaylarının matematiksel etkinlik kavramına dair algıları, etkinliği nasıl tanımladıkları, etkinliği oluşturan unsurlar, öğretmen ve öğrencinin etkinlikteki rolleri ve iyi bir etkinlikte bulunması gereken özelliklere dair verdikleri yanıtlar ayrı başlıklar altında verilmiştir. Her bir soruya dair öğretmen adaylarının yanıtlarından oluşturulan kodlar, kategoriler ve alt kategoriler tablolarda sunulmuştur. Öğretmen adaylarının ifadelerinden elde edilen kodların sıklıkları öğrenim görülen bölümlere göre ayrı ayrı belirtilmiş ve toplam öğrenci sayısına göre bu sıklıkların yüzdelikleri tablolarda verilmiştir.

\section{1. Öğretmen adaylarının etkinlik kavramına dair algıları}

Tablo 2'de görüldüğü gibi, öğretmen adaylarının yanıtlarını "amaç", "nitelik" ve "isimlendirme" olarak üç kategoride incelemek mümkündür. Sınıf öğretmeni adaylarının verdiği cevaplarda amaç kategorisinde çoğunlukla belirtilen, etkinliklerin pekiştirme $(f=26)$, öğretme $(f=10)$, somutlaştırma $(f=7)$ ve anlamlı ögrenme $(f=3)$ amacıyla kullanılması şeklinde olmuştur. Matematik öğretmen adayları ise bu kategoride, sınıf öğretmeni adaylarına kıyasla daha az sıklıkla olmak üzere, pekiştirme $(f=3)$, somutlaştırma $(f=3)$, günlük hayat ilişsilendirmesi $(f=2)$, anlamlı ögrenme $(f=3)$ ve ögrencinin aktif olması $(f=2)$ gibi amaçlar üzerinde durmuşlardır.

Nitelik kategorisinde (Tablo 2), her iki bölüm öğretmen adayları tarafından sözü edilen en sık kodlar, öğretici olması, dikkat çekici olması, ĕglenceli olması ve yaratıcı olması gibi niteliklerdir. Bunlara ek olarak, Tablo 2'de belirtilmeyen diğer kodlar: sınıfta yapılan, sosyal, zihinsel şeklindeki nitelendirmelerdir.

İsimlendirme kategorisinde (Tablo 2), sınıf öğretmeni adaylarının en sık belirttiği kodlar alıştırma $(f=13)$, materyal $(f=11)$, çalışma $(f=7)$ ve faaliyet $(f=7)$ olarak belirlenmiştir. Bunları pekiştireç $(f=3)$, oyun $(f=3)$, grup çalı̧̧ması $(f=2)$, eğlence ve yarışma $(f=2)$ izlemektedir. Matematik öğretmen adaylarının bu kategoride sıklıkla ifade ettiği bir isimlendirmeye rastlanmamıştır. 
Kurt Erhan, G., Yiğitcan Nayir, Ö. (2017). Investigation of the concept of activity in different dimensions according to the perspective of pre-service teachers. International Journal of Social Sciences and Education Research, 3(1), 283-296.

Sadece iki öğretmen adayı etkinliği faaliyet $(f=2)$ şeklinde isimlendirmiştir. Bu çalışmada isimlendirme kategorisinde tanımlanan etkinlik kavramı, Uğurel ve Bukova-Güzel'in (2010) çalışmasında bir ürün belirteci (s.337) olarak ele alınmıştır. Ayrıca ilgili kavrama ulaşmak için kullanılan kavram haritaları, tablo, grafik ve oyunlar gibi uygulamada kullanılan somut araçlar olarak tanımlanmıştır (Olkun ve Toluk, 2005). Tablo 2'de belirtilmeyen, ancak iki bölümdeki öğretmen adayları tarafından sözü edilen diğer isimlendirmeler, kavram yanılglları, proje, sunum, görev, uygulamalar (öğretimi kolaylaştıran), bireysel çalışma, gezi düzenleme, drama şeklindedir.

Tablo 2. Öğretmen Adaylarının "Etkinlik deyince aklıma gelen ilk şey..." cümlesinin tamamlanmasında verdiği yanıtlar

\begin{tabular}{|c|c|c|c|c|c|}
\hline \multirow[b]{2}{*}{ Kategoriler } & \multirow[b]{2}{*}{ Kodlar } & \multicolumn{4}{|c|}{ Bölümlere göre dağılım } \\
\hline & & $\begin{array}{c}\mathbf{f} \\
\text { (S. Ö.) }\end{array}$ & $\begin{array}{c}\% \\
\text { (S. Ö.) }\end{array}$ & $\begin{array}{c}\mathbf{f} \\
\text { (M. Ö.) }\end{array}$ & $\begin{array}{c}\% \\
\text { (M. Ö.) }\end{array}$ \\
\hline \multirow{7}{*}{ Amaç } & Pekiştirme & 26 & 38 & 3 & 10 \\
\hline & Öğretme & 10 & 14 & - & \\
\hline & Somutlaştırma & 7 & 10 & 3 & 10 \\
\hline & Anlamlı öğrenme & 3 & 4 & 3 & 10 \\
\hline & Günlük hayatla ilişkilendirme & - & & 2 & 6 \\
\hline & Aktif öğrenci & - & & 2 & 6 \\
\hline & Psiko-motor gelişim & - & & 1 & 3 \\
\hline \multirow{4}{*}{ Nitelik } & Öğretici & 4 & 6 & 3 & 10 \\
\hline & Dikkat çekici & 4 & 6 & - & \\
\hline & Eğlenceli & 3 & 4 & 1 & 3 \\
\hline & Yaratıcı & 2 & 3 & - & \\
\hline \multirow{9}{*}{ İsimlendirme } & Alıştırma & 13 & 19 & - & \\
\hline & Materyal & 11 & 16 & 1 & 3 \\
\hline & Çalışma & 7 & 10 & - & \\
\hline & Faaliyet & 7 & 10 & 2 & 6 \\
\hline & Pekiştireç & 3 & 4 & 1 & 3 \\
\hline & Oyun & 3 & 4 & - & \\
\hline & Grup çalışması & 2 & 3 & - & \\
\hline & Eğlence, Yarışma & 2 & 3 & 1 & 3 \\
\hline & Drama & 1 & 2 & - & - \\
\hline
\end{tabular}

Sınıf öğretmeni (SÖ) ve matematik öğretmeni (MÖ) adaylarının matematik öğretimi göz önünde bulundurularak "etkinlik deyince aklıma gelen ilk şey..." cümlesini tamamlarken çeşitli görünmesine rağmen anlam bakımından benzer yanıtlar verdikleri görülmektedir. Bu yanıtlarda, öğretmen adaylarının büyük çoğunluğu, akıllarına gelen ilk şey sorulmasına rağmen, birden fazla tanımlama ile ifade ettikleri görülmüştür. 4. sınıfta öğrenim gören bir SÖ adayı, "Kavramsal yanılgıya düşmeden ilkokul seviyesindeki çocuğa konuyu somutlaştırarak, kendisini de sürece katan bütünsel eylemlerdir. Bu bütünsel eylemler gerek zihinsel katılım gerekse fiziksel katılım ile gerçekleştirilir." şeklinde etkinlik deyince aklına gelen ilk şeyi ifade etmiştir. 4. sınıfta öğrenim gören bir MÖ adayı, "bir konunun iyi anlaşılır ve unutulmayacak şekilde anlatılmasını sağlayan araç." şeklinde cümleyi tamamlamıştır.

Öğretmen adaylarından birkaçı etkinlik deyince aklıma gelen ilk şey cümlesini sadece bir kelime ile (Ör: eğlence, yarışma, drama, materyal) tamamlamışlardır. 
Kurt Erhan, G., Yiğitcan Nayir, Ö. (2017). Etkinlik kavramının öğretmen adaylarının bakış açısıyla farklı boyutlarda incelenmesi. International Journal of Social Sciences and Education Research, 3(1), 283-296.

\subsection{Etkinliğin tanımlanması}

Öğretmen adaylarının "etkinliği nasıl tanımlarsınız?" sorusuna verdiği yanıtlar incelendiğinde, "etkinlik deyince aklıma gelen ilk şey..." cümlesini tamamlarken kullandıkları tanımlamalara benzer cevaplar verdikleri, ancak buradaki yanıtların daha uzun ve cümleler şeklinde yazıldığı görülmüştür. Bu bölümde de benzer şekilde "amaç", "nitelik" ve "isimlendirme" kategorileri belirlenmiştir. Sınıf öğretmeni adayları, "Etkinliği nasıl tanımlarsınız?" sorusuna, "amaç" kategorisinde konuyu ögrenmek ve anlamak $(f=19)$, pekiştirmek $(f=15)$, aktif katılımı sağlamak $(f=5)$ ve farklı düşünmeyi sağlamak $(f=3)$ şeklinde isimlendirilen yanıtları vermişlerdir. Belirtilen kalıcı ögrenmeyi sağlamak, somutlaştırmak, etkin ders işlemek ve beceri geliştirmek gibi yanıtlar her iki bölümün öğretmen adayları tarafından verilmiştir.

"Nitelik" kategorisinde, sınıf öğretmeni adayları için dinlendirici olması, eğitici/öğretici olmasl, zevk vermesi ve ögrenci seviyesine uygun olmasl, verimli olmasl, görsel olmast gibi nitelikler ortaya çıkmaktadır. Matematik öğretmenleri açısından ise zihinsel gelişimi etkileyen, öğrenciyi merkeze alan ve ilgi çekici olması ön plana çıkmaktadır. "İsimlendirme" kategorisinde ise çalışma, faaliyet, örnek ve alıştırmalar, bireysel ve grup çalışmalarl, uygulamalar, materyal, somut verilerin tümü iki grup tarafından da belirtilmiştir.

$\mathrm{Bu}$ bölümde, yukarıda belirtilen kategorilere ek olarak ortaya çıkan bazı alt kategoriler belirlenmiştir. Bu alt kategoriler nasıl, nerede ve ne zaman şeklindedir. Öğretmen adaylarının, yanıtlarında etkinliği bir amaç, nitelik veya isimlendirme olarak tanımlarken, aynı zamanda bu amacın nasıl, nerede veya ne zaman gerçekleştiği boyutlarının herhangi birinden söz ettikleri görülmüştür. Sözü edilen bu alt kategoriler her bir kategori altında bulunmadığından ve öğretmen adaylarının küçük bir kısmı tarafından belirtildiğinden Tablo 3 'te ayrıca belirtilmemiş, sadece öğretmen adaylarının ifadelerinden örnekler verilerek aşağıda sunulmuştur.

4. sınıfta öğrenim gören bir SÖ adayı etkinliği, "Öğrencilerin dersten sonra anlama, kavrama için yaptı̆̆ uygulamalar." ş̧eklinde tanımlamıştır. Aynı sınıfta öğrenim gören bir MÖ adayı "Dersten sonra ve ders esnasında, derste öğretilen içerik ile ilgili alıştırma, pekiştirme çalışmaları; çeşitli uygulamalar yapma, etkin olarak öğrencilerin katılımıyla săglanan uygulamalardır." şeklinde tanımını yazmıştır. Bu ifadelerden etkinliğin yapılış amacı, ne zaman yapıldığ 1 ve nasıl isimlendirildiği anlaşılmaktadır. 3. sınıfta öğrenim gören bir başka SÖ adayı "Etkinlik, ders sırasında ögretmenin konuyu pekiştirmek için kullandığı uygulamalardır." şeklinde tanımlama yapmıştır. Bu ifadeden anlaşıldığı gibi, etkinliğin ne zaman, ne amaçla kullanıldığı ve nasıl isimlendirildiği görülmektedir. 4. sınıfta öğrenim gören bir diğer MÖ adayının "Sinıf ortamı dışında, daha farklı ve doğal bir ortamda dersle ilgili kendi materyallerini oluşturmak." ş̧eklindeki ifadesinden etkinliğin nerede ve hangi amaçla yapıldığı bildirilmektedir. 
Kurt Erhan, G., Yiğitcan Nayir, Ö. (2017). Investigation of the concept of activity in different dimensions according to the perspective of pre-service teachers. International Journal of Social Sciences and Education Research, 3(1), 283-296.

Tablo 3. Öğretmen adaylarının “Etkinliği nasıl tanımlarsınız?” sorusuna verdiği yanıtlar

\begin{tabular}{|c|c|c|c|c|c|}
\hline \multirow[b]{2}{*}{ Kategoriler } & \multirow[b]{2}{*}{ Kodlar } & \multicolumn{4}{|c|}{ Bölümlere göre dağılım } \\
\hline & & $\begin{array}{c}\mathbf{f} \\
\text { (S. Ö.) }\end{array}$ & $\begin{array}{c}\% \\
\text { (S. Ö.) }\end{array}$ & $\begin{array}{c}\mathbf{f} \\
\text { (M. } \\
\text { Ö.) }\end{array}$ & $\begin{array}{c}\text { \% } \\
\text { (M. } \\
\text { Ö.) }\end{array}$ \\
\hline \multirow{13}{*}{ Amaç } & Konuyu öğrenmek / anlamak & 19 & 28 & 2 & 6 \\
\hline & Pekiştirmek & 15 & 22 & 3 & 10 \\
\hline & Aktif katılımı sağlamak & 5 & 7 & 1 & 3 \\
\hline & Farklı düşünmeyi sağlamak & 3 & 4 & - & \\
\hline & Somutlaştırmak & 2 & 3 & 6 & 19 \\
\hline & Kalıcı öğrenme & 2 & 3 & 1 & 3 \\
\hline & Etkin ders işlemek & 1 & 1 & 2 & 6 \\
\hline & Beceri geliştirmek & 1 & 1 & 1 & 3 \\
\hline & $\begin{array}{l}\text { Fikirlerini özgürce dile getirmesini } \\
\text { sağlamak }\end{array}$ & 2 & 3 & - & \\
\hline & $\begin{array}{l}\text { Konuyu anlayıp anlamadığını belir- } \\
\text { lemek }\end{array}$ & 1 & 1 & - & \\
\hline & Derse hazırlanmak & 1 & 1 & - & \\
\hline & Dikkati yoğunlaştırmak & 1 & 1 & - & \\
\hline & $\begin{array}{l}\text { Günlük hayat ilişsilendirmesi yap- } \\
\text { mak }\end{array}$ & - & & 1 & 3 \\
\hline \multirow{8}{*}{ Nitelik } & Eğitici/öğretici & 2 & 3 & - & \\
\hline & Eğlenceli, ilgi çekici & 2 & 3 & - & \\
\hline & Verimli & 2 & 3 & - & \\
\hline & Öğrenci seviyesine uygun & 1 & 1 & - & \\
\hline & Bilgiyi somutlaştıran & 1 & 1 & - & \\
\hline & Görsel & 1 & 1 & - & \\
\hline & Dinlendirici & 1 & 1 & - & \\
\hline & Amaci olan & 1 & 1 & - & \\
\hline \multirow{16}{*}{ İsimlendirme } & Çalışma & 11 & 16 & - & \\
\hline & Faaliyet & 6 & 9 & 1 & 3 \\
\hline & Uygulama & 5 & 7 & 1 & 3 \\
\hline & Örnek ve alıştırmalar & 4 & 6 & 1 & 3 \\
\hline & Bireysel ve grup çalışmaları & 4 & 6 & - & \\
\hline & Hareketler bütünü & 3 & 4 & - & \\
\hline & Pekiştireç & 2 & 3 & 3 & 10 \\
\hline & Materyal & 2 & 3 & 2 & 6 \\
\hline & Somut verilerin tümü & 1 & 1 & 3 & 10 \\
\hline & Eğitmenler tarafindan hazırlanan & 1 & 1 & - & \\
\hline & Derse teşvik eden & 1 & 1 & - & \\
\hline & Yarışma, oyun & 1 & 1 & - & \\
\hline & Öğretici oyunlar & 1 & 1 & - & \\
\hline & Konuya ön hazırlık & 1 & 1 & - & \\
\hline & Zihinsel gelişimi etkileyen & - & & 1 & 3 \\
\hline & Öğrenciyi merkeze alan & - & & 1 & 3 \\
\hline
\end{tabular}

\subsection{Etkinliği oluşturan unsurlar}

Öğretmen adaylarının "Etkinliği oluşturan unsurlar nelerdir?" sorusuna verdiği yanıtlar, Tablo 4'te görüldüğü gibi, dört kategoride toplanmıştır. Temel unsurlar kategorisinde: ögrrenci, öğretmen, mekân (ortam) ve akran kodları görülmektedir. Her iki bölüm öğretmen adaylarının belirttiği bu kodların frekanslarının mevcut sayıları oranında birbirine yakın olduğu görülmektedir. 
Kurt Erhan, G., Yiğitcan Nayir, Ö. (2017). Etkinlik kavramının öğretmen adaylarının bakış açısıyla farklı boyutlarda incelenmesi. International Journal of Social Sciences and Education Research, 3(1), 283-296.

Yazılı dokümanlar kategorisinde, sınıf öğretmen adaylarının sıklıkla ifade ettiği kodlar yer almaktadır. Bunlar: konu (içerik), kazanım, plan, sınıf düzeyi, amaç, süre şeklindeki kodlardır. Süreç-Ürün unsurları kategorisinde, ortaya çıkan ve her iki bölümün öğretmen adayları tarafından sıklıkla belirtilen unsur materyaller olarak ifade edilmiştir. Bu kategorideki diğer unsurlar, görseller, oyun, soru, teknoloji, posterler gibi etkinlik sürecinde kullanılan veya etkinliğin sonunda bir ürün olarak ortaya çıkan unsurlardır. Duyuşsal unsurlar kategorisinde, düşük sıklıklarda belirtilen algl, pekiştireç, ögrencinin motivasyonu ve iletişim kodları bulunmaktadır.

Tablo 4. Öğretmen adaylarının "Etkinliği oluşturan unsurlar nelerdir?" sorusuna verdiği yanıtlar

\begin{tabular}{|c|c|c|c|c|c|}
\hline \multirow{2}{*}{ Kategoriler } & \multirow[b]{2}{*}{ Kodlar } & \multicolumn{4}{|c|}{ Bölümlere göre dağılım } \\
\hline & & $\begin{array}{c}\mathbf{f} \\
\text { (S. Ö.) }\end{array}$ & $\begin{array}{c}\% \\
\text { (S. Ö.) }\end{array}$ & $\begin{array}{c}\mathbf{f} \\
\text { (M. Ö.) }\end{array}$ & $\begin{array}{c}\% \\
\text { (M. Ö.) }\end{array}$ \\
\hline \multirow{4}{*}{ Temel unsurlar } & Öğrenci & 12 & 17 & 9 & 29 \\
\hline & Öğretmen & 11 & 16 & 8 & 26 \\
\hline & Mekan (Ortam) & 9 & 13 & 5 & 16 \\
\hline & Akran & 1 & 1 & - & \\
\hline \multirow{9}{*}{ Yazılı dokümanlar } & Konu (İçerik) & 7 & 10 & 1 & 3 \\
\hline & Kazanım & 5 & 7 & - & \\
\hline & Plan & 5 & 7 & 1 & 3 \\
\hline & Etkinlik izlencesi & 1 & 1 & 1 & 3 \\
\hline & Sınıf düzeyi & 3 & 4 & - & \\
\hline & Amaç & 3 & 4 & - & \\
\hline & Süre & 3 & 4 & - & \\
\hline & Yöntem & 1 & 1 & - & \\
\hline & Kaynaklar & - & & 1 & 3 \\
\hline \multirow{11}{*}{$\begin{array}{l}\text { Süreç-Ürün unsur- } \\
\text { ları }\end{array}$} & Materyal & 21 & 30 & 11 & 35 \\
\hline & Görseller & 6 & 9 & 2 & 6 \\
\hline & Oyun & 2 & 3 & 3 & 10 \\
\hline & Gezi & - & & 2 & 6 \\
\hline & Yap-boz, bulmaca & 2 & 3 & - & \\
\hline & Soru & 3 & 4 & - & \\
\hline & Uygulama & 1 & 1 & - & \\
\hline & Çalışma kağıdı & 1 & 1 & - & \\
\hline & Teknoloji & - & & 1 & 3 \\
\hline & Posterler & - & & 1 & 3 \\
\hline & Videolar & - & & 1 & 3 \\
\hline \multirow{4}{*}{ Duyuşsal unsurlar } & Alg1 & 1 & 1 & - & \\
\hline & Pekiştireç & 1 & 1 & - & \\
\hline & Motivasyon & 1 & 1 & 1 & 3 \\
\hline & İletişim & - & & 1 & 3 \\
\hline
\end{tabular}

\subsection{Etkinlikte öğrencinin rolü}

"Etkinlikte öğrencinin rolü ne olmalıdır?" sorusuna verilen yanıtların büyük çoğunluğu uygulama aşamasında olmalıdır şeklinde belirtilmiştir. Tablo 5 'te görüldüğü gibi, her iki bölümün öğretmen adayları tarafından sıklıkla belirtilen rol öğrencinin aktif olmasıdır. Belirtilen diğer roller: istekli, etkinliğin merkezinde yer alan, merakll, yönergeleri yerine getiren, sorumluluk sahibi şeklinde sıralanabilir. Öğretmen adaylarının görüşlerini destekleyen bir bulgu Batdı'nın (2014) çalışmasında belirtilmiş; etkinliklerde öğrencilerin motivasyonlarının ve merak düzeylerinin yüksek tutulduğu sonucu ortaya çıkmıştır. Öğrencilerin etkin dinleyici, düşünen ve sorgulayan rolleri her iki grup tarafından da belirtilmiştir. Yine bu sonuç, Batdı'nın (2014) çalışmasında belirttiği, et- 
Kurt Erhan, G., Yiğitcan Nayir, Ö. (2017). Investigation of the concept of activity in different dimensions according to the perspective of pre-service teachers. International Journal of Social Sciences and Education Research, 3(1), 283-296.

kinlik temelli öğretimde öğrencinin kendi deneyimleriyle birlikte kendi sorularını sorarak öğrenme ortamında yer alması gerektiği görüşüyle tutarlılık göstermektedir. Bunlara ek olarak, paylaşımcı, konuya hakim, hayal gücünü kullanan, önceki bilgilerle ilişkilendirme yapabilen, geri bildirimlerde doğru ve net olan öğrenci rolleri belirtilmiştir.

Tablo 5. Öğretmen adaylarının “Etkinliklerde öğrencinin rolü nedir?” sorusuna verdiği yanıtlar

\begin{tabular}{lcccc}
\hline & \multicolumn{3}{c}{ Bölümlere göre dağılım (f) } \\
\hline Öğrenci Rolleri & $\begin{array}{c}\text { f } \\
\text { (S. Ö.) }\end{array}$ & $\begin{array}{c}\text { \% } \\
\text { (S. Ö.) }\end{array}$ & $\begin{array}{c}\mathbf{f} \text { (M. Ö.) } \\
\text { (M. Ö.) }\end{array}$ \\
\hline Aktif & 33 & 48 & 17 & 55 \\
\hline İstekli & 7 & 10 & 2 & 6 \\
\hline Merkezde & 2 & 3 & 1 & 3 \\
\hline Yaparak yaşayarak öğrenen & 3 & 4 & - & - \\
\hline Meraklı & 2 & 3 & 1 & 3 \\
\hline İlgili & 2 & 3 & - & - \\
\hline Yönergeleri yerine getiren & 2 & 3 & 4 & 13 \\
\hline Sorumluluk sahibi & 2 & 3 & - & - \\
\hline Etkin dinleyici & 1 & 1 & 1 & 3 \\
\hline Araştırmacı & 1 & 1 & - & - \\
\hline Düşünen/sorgulayan & 1 & 1 & 1 & 3 \\
\hline Paylaşımc & 1 & 1 & - & - \\
\hline Konuya hakim & 1 & 1 & - & - \\
\hline Hayal gücünü kullanan & - & - & 1 & 3 \\
\hline Önceki bilgilerle ilişkilendirme yapabilen & - & - & 1 & 3 \\
\hline Geri bildirimlerde doğru ve net olan & - & - & 1 & 3 \\
\hline
\end{tabular}

\subsection{Etkinlikte ögretmenin rolü}

"Etkinlikte öğretmenin rolü ne olmalıdır?" sorusuna verilen yanıtlar, Tablo 6'da görüldüğü gibi iki kategoride toplanmıştır. Öğrenciye yönelik roller kategorisinde, her iki bölümün öğretmen adayları tarafından en s1k belirtilen rolün ögrenciyi yönlendiren/ rehber olduğu görülmektedir.

Tablo 6. Öğretmen adaylarının “Etkinliklerde öğretmenin rolü nedir?” sorusuna verdiği yanıtlar

\begin{tabular}{|c|c|c|c|c|c|}
\hline \multirow{2}{*}{ Kategoriler } & \multirow[b]{2}{*}{ Kodlar } & \multicolumn{4}{|c|}{ Bölümlere göre dağılım (f) } \\
\hline & & $\begin{array}{c}\mathbf{f} \\
\text { (S. } \ddot{O} .)\end{array}$ & $\begin{array}{c}\% \\
\text { (S. Ö.) }\end{array}$ & $\begin{array}{c}\text { f } \\
(\mathbf{M} . \ddot{O} .)\end{array}$ & $\begin{array}{c}\% \\
\text { (M. Ö.) }\end{array}$ \\
\hline \multirow{9}{*}{$\begin{array}{l}\text { Öğrenciye } \\
\text { yönelik rol- } \\
\text { ler }\end{array}$} & Öğrenciyi yönlendiren/ Rehber & 29 & 42 & 14 & 45 \\
\hline & $\begin{array}{l}\text { Öğrencinin ilgi ve ihtiyaçlarını } \\
\text { dikkate alan }\end{array}$ & 12 & 17 & 5 & 16 \\
\hline & Öğrenciyi aktif hale getiren & 10 & 14 & 6 & 19 \\
\hline & Etkinliği planlayan & 8 & 12 & 2 & 6 \\
\hline & $\begin{array}{l}\text { İhtiyaç duyulan durumda yar- } \\
\text { dımcı olan }\end{array}$ & 4 & 6 & 2 & 6 \\
\hline & $\begin{array}{l}\text { Konunun daha iyi kavranma- } \\
\text { sinı sağlayan }\end{array}$ & 3 & 4 & 1 & 3 \\
\hline & Yönergeleri iyi belirleyen & 3 & 4 & - & \\
\hline & İlgi çekici etkinlikler bulan & 2 & 3 & 1 & 3 \\
\hline & Sinıf ortamını düzenleyen & 1 & 1 & - & \\
\hline \multirow{6}{*}{$\begin{array}{l}\text { Bireysel rol- } \\
\text { ler }\end{array}$} & Lider & 3 & 4 & 2 & 6 \\
\hline & Empati kurabilen & 2 & 3 & 1 & 3 \\
\hline & Adil & 2 & 3 & - & \\
\hline & Öğrenci fikirlerine önem veren & 2 & 3 & - & \\
\hline & İlgili & 1 & 1 & - & \\
\hline & Gözlemci & 1 & 1 & 1 & 3 \\
\hline
\end{tabular}


Kurt Erhan, G., Yiğitcan Nayir, Ö. (2017). Etkinlik kavramının öğretmen adaylarının bakış açısıyla farklı boyutlarda incelenmesi. International Journal of Social Sciences and Education Research, 3(1), 283-296.

Öğretmenin öğrencinin ilgi ve ihtiyaçlarını dikkate alan rolü, öğretmen adayları arasında sıklıkla belirtilen bir başka roldür. Bunları, öğrenciyi aktif hale getiren, etkinliği planlayan, ihtiyaç duyulan durumda yardımcı olan, konunun daha iyi kavranmasını sağlayan, yönergeleri iyi belirleyen, ilgi çekici etkinlikler bulan ve sınıf ortamını düzenleyen roller izlemektedir. Bireysel roller kategorisinde empati kurabilen, adil, ögrenci fikirlerine önem veren, ilgili ve gözlemci rolleri ifade edilmiştir. Öğretmen adaylarının bu görüşleri, Van De Walle'in (2007) etkinlik yürütülürken öğretmenin aktif dinleyici olması gerektiği görüşüyle bağdaşmaktadır. Van De Walle (2007), öğretmenin etkinlik öncesinde, öğrencilerin önceki bilgilerini aktif hale getirmesinin, yönergeleri açık ve net bir şekilde ortaya koyarak beklentilerini ifade etmesinin; etkinlik sırasında öğrencileri serbest bırakmasının, aktif dinleyici rolüyle uygun ipuçları vererek öğrencilere değerli fikirler sunmasının önemini belirtmiştir.

\subsection{Etkinlik özellikleri}

“İyi bir etkinlikte bulunması gereken özellikler nelerdir?” sorusuna, Tablo 7'de görüldüğü gibi, her iki bölümün öğretmen adayları tarafından verilen en sık yanıtlar; seviyeye uygun, konuyla ilgili, dikkat çekici, açık ve net, öğretici, plan/programı olan, amaca uygun şeklindeki özeliklerdir. Bunları, yeterli görsellik içeren, iletişime uygun, eğlendirici, , materyallerle desteklenmeli, bütüncül olmalı gibi özellikler izlemektedir.

Tablo 7. Öğretmen adaylarının "Etkinliği oluşturan özellikler nelerdir?" sorusuna verdiği yanıtlar

\begin{tabular}{|c|c|c|c|c|}
\hline \multirow[b]{2}{*}{ Kodlar } & \multicolumn{4}{|c|}{ Bölümlere göre dağılım (f) } \\
\hline & f (S. Ö.) & \% (S. Ö.) & f (M. Ö.) & \% (M. Ö.) \\
\hline Seviyeye uygun & 16 & 23 & 6 & 19 \\
\hline Konuyla ilgili & 13 & 19 & 9 & 29 \\
\hline Dikkat çekici olmalı & 12 & 17 & 4 & 13 \\
\hline Açık ve net olmalı & 10 & 14 & 4 & 13 \\
\hline Öğretici & 8 & 12 & 4 & 13 \\
\hline Plan /programı olmalı & 8 & 12 & 1 & 3 \\
\hline Amaca uygun olmalı & 7 & 10 & 3 & 10 \\
\hline Yeterli görsellik içeren & 6 & 9 & 2 & 6 \\
\hline İletişime uygun & 6 & 9 & 1 & 3 \\
\hline Eğlendirici & 5 & 7 & 2 & 6 \\
\hline Materyallerle desteklenmeli & 5 & 7 & 1 & 3 \\
\hline Bütüncül olmalı & 5 & 7 & - & - \\
\hline $\begin{array}{l}\text { Bireysel farklılıklara hitap } \\
\text { eden }\end{array}$ & 4 & 6 & 5 & 16 \\
\hline Verimli & 4 & 6 & 1 & 3 \\
\hline Aktif katılım olmalı & 3 & 4 & 1 & 3 \\
\hline $\begin{array}{l}\text { Daha iyi anlamayı, pekiştir- } \\
\text { meyi sağlamalı }\end{array}$ & 3 & 4 & 1 & 3 \\
\hline Zamanı doğru kullanmalı & 3 & 4 & 3 & 10 \\
\hline Yaratıcı olmalı & 2 & 3 & 2 & 6 \\
\hline Öğrenci odaklı & 1 & 1 & 1 & 3 \\
\hline Kapsayıc1 & 1 & 1 & 1 & 3 \\
\hline İlişkilendirme olmalı & 1 & 1 & 2 & 6 \\
\hline $\begin{array}{l}\text { Kavram yanılgisina neden ol- } \\
\text { mamalı }\end{array}$ & - & - & 2 & 6 \\
\hline Somut & 1 & 1 & - & - \\
\hline Hatırlatıcı olmalı & 1 & 1 & - & - \\
\hline Sade olmalı & - & - & 1 & 3 \\
\hline Uygulanabilir olmalı & - & - & 1 & 3 \\
\hline Geliştirilebilir olmalı & - & - & 1 & 3 \\
\hline
\end{tabular}


Kurt Erhan, G., Yiğitcan Nayir, Ö. (2017). Investigation of the concept of activity in different dimensions according to the perspective of pre-service teachers. International Journal of Social Sciences and Education Research, 3(1), 283-296.

Öğretmen adaylarına göre iyi bir etkinlikte olması gereken diğer özellikler Tablo 7'de görülmektedir. Etkinliğin öğrenmeyi kolaylaştıran, ilgi çekici, eğlenceli, aktif katılımı sağlaması gibi özellikleri Kösterelioğlu, Bayar ve Akın Kösterelioğlu (2014) tarafından yapılan çalışmanın bulgularıly benzerlikler göstermektedir.

\section{Sonuç ve öneriler}

Bu çalışmada, öğretmen adaylarının etkinlik kavramını oldukça farklı betimlemelerle tanımladıkları görülmüştür. Bu farklı1ık matematiksel etkinlik kavramının net bir tanımının olmamasından kaynaklanıyor olabilir. Bu sonuç, Bozkurt'un (2012) matematik öğretmenlerinin matematiksel etkinlik kavramına dair algılarını inceledikleri çalışmanın bulgularıyla tutarlılık göstermektedir. Bununla birlikte, en sık kullanılan betimlemeler: konuyu öğrenmek, anlamak, pekiştirmek, kalıcı öğrenmeyi ve aktif katılımı sağlamak, somutlaştırmak, etkin ders işlemek ve beceri geliştirmek amaciyla planlanan, dinlendirici, öğretici, zevkli, öğrenci seviyesine uygun, verimli, görsel çalışma, faaliyet, örnek ve alıştırmalar, bireysel ve grup çalışmaları, uygulamalar ve materyallerin tümüdür.

Öğretmen adaylarının yanıtlarında çeşitliliğin fazla olduğu görülmektedir. Öğretmen adayları etkinlik kavramına dair düşüncelerini belirtirken birden fazla betimlemeyle yanıtlarını vermişlerdir. Tablolarda görülen kodların dağılımlarının çalışma grubu sayısından fazla olması bu sebeptendir. Bölümlere göre öğretmen adaylarının düşüncelerinin belirgin bir şekilde farklılaşmadığ söylenebilir. Yalnız, Tablo 3 incelendiğinde, yüzdelik dağılım bakımından, matematik öğretmeni adayları sınıf öğretmeni adaylarına kıyasla etkinlik tanımında 'somutlaştırma' amacını daha belirgin vurgulamışlardır. Bu matematiğin soyut bir disiplin olması ve matematik öğretmeni adaylarının bu konudaki farkındalıklarının daha belirgin olması şeklinde yorumlanabilir.

Diğer taraftan etkinliği oluşturan unsurlar, etkinlikte öğrenci ve öğretmen rolleri konusunda öğretmen adaylarının verdiği yanıtlar belirli bir çerçevede birleşmiştir. Seviyeye uygun, konuyla ilgili, açık ve net, dikkat çekici, amaca uygun, öğretici, eğlendirici, yeterli görsellikte, öğrenci odakl1, materyallerle desteklenen etkinliğin materyaller, öğrenci, öğretmen, ortam ve konu (içerik) unsurları olarak belirtilirken, öğrenci aktif ve merkezde, yönergeleri uygulayan, sorgulayıp düşünce üreten, meraklı ve ilgili olmalıdır. Öğretmen ise kendini ikinci planda tutmalı, rehber ve lider konumunda, anlaşılır bir dille yönergeleri açıklamalı, yol gösterici olmalı ve öğrencileri engelleyici olumsuz tutumlardan kaçınmalıdır.

Etkinlik kavramının daha iyi anlaşılması için nasıl tanımlandığının doğru bir şekilde ortaya konulması gerekmektedir. Bu anlamda, öğretmen adaylarının etkinlik kavramını nasıl algıladıklarına dair sınıf içi tartışmalara yer verilmelidir. İyi bir etkinlikte olması gereken özelliklerin, öğrenci ve öğretmen rollerinin neler olması gerektiğine dair ulaşılan fikirler bir araya getirilerek, etkili bir etkinlik sürecinin yapılandırılması için gerekli kavramsal alt yapı sağlanmış olacaktır. Öğretmen adaylarının alg1 ve eğilimlerinin kavramsal boyutta belirlenmesinden sonra, ilgili derslerde hazırladıkları etkinlikler incelenerek ifade ettikleri özellikleri ne kadar içerdiği araştırılabilir. Öğretmen adaylarının etkinlik uygulamaları gözlemlenerek bu uygulamaların hangi özelliklere sahip olduğu incelenebilir. 
Kurt Erhan, G., Yiğitcan Nayir, Ö. (2017). Etkinlik kavramının öğretmen adaylarının bakış açısıyla farklı boyutlarda incelenmesi. International Journal of Social Sciences and Education Research, 3(1), 283-296.

\section{Kaynakça}

Baş, T. ve Akturan, U. (2008). Nitel araştırma metotları. Ankara: Seçkin Yayıncılık

Batdı, V. (2014). Etkinlik temelli öğrenme yaklaşımının akademik başarıya etkisi (meta-analitik ve tematik bir çalışma). E-International Journal of Educational Research. 5(3), 39-55. doi: http://dx.doi.org/10.19160/e-ijer.12976

Bozkurt, A. (2012). Matematik öğretmenlerinin matematiksel etkinlik kavramına dair algıları. Ĕ̆itim ve Bilim, 37(166), 101-115

Gürbüz, R. (2010). The effect of activity-based instruction on conceptual development of seventh grade students in probability. International Journal of Mathematical Education in Science and Technology. 41(6), 743-767.

Kösterelioğlu, İ. ve Yapıcı, M. (2016). Etkinlik temelli öğrenme sürecinin öğretmen adaylarının yapılandırmacı öğrenme ortamı algılarına etkisi. International Journal of Human Sciences, 13(1), 1342-1354. doi: 10.14687/ijhs.v13i1.3640

Kösterelioğlu, İ., Bayar, A. ve Akın Kösterelioğlu (2014). Öğretmen eğitiminde etkinlik temelli öğrenme süreci: Bir durum araştırması. Turkish Studies, International Periodical For The Languages, Literature and History of Turkish or Turkic. 9(2), 1035-1047.

Küpcü, A. R. (2012). Etkinlik temelli öğretim yaklaşımının ortaokul öğrencilerinin orantısal problemleri çözme başarısına etkisi. Ahi Evran Üniversitesi Kırşehir Eğitim Fakültesi Dergisi (KEFAD), 13(3), 175-206.

Olkun, S. ve Toluk, Z. (2005). Illköğretimde etkinlik temelli matematik öğretimi. Anı Yayıncılık, Ankara.

TDK. Türk Dil Kurumu sözlüğü ([Online] http://www.tdk.gov.tr/ adresinden 18.05.2016 tarihinde indirilmiştir.)

Uğurel, I. ve Bukova-Güzel, E. (2010). Matematiksel öğrenme etkinlikleri üzerine bir tartışma ve kavramsal bir çerçeve önerisi. Hacettepe Üniversitesi Ĕ̆itim Fakültesi Dergisi, 39, 333-347.

Uşun, S. ve Gökçen, E. (2010). İlköğretim ikinci kademede etkinlik temelli öğretim yaklaşımının öğrencilerin matematik dersine yönelik tutumlarına etkisi. International Online Journal of Educational Sciences, 2(2), 532- 561.

Van De Walle, J. A. (2007). Elementary and middle school mathematics: Teaching developmentally. 6th edition. Pearson Education. 
Kurt Erhan, G., Yiğitcan Nayir, Ö. (2017). Investigation of the concept of activity in different dimensions according to the perspective of pre-service teachers. International Journal of Social Sciences and Education Research, 3(1), 283-296.

\section{Extended abstract in English}

It is known that providing the learning environments with activities supporting the learners for research and questioning, communication, critical thinking and express their ideas are important in education. Fundamentals of mathematics learning needs constructive learning environments where students acquire mathematical ideas, solve problems by using the skills of reasoning and relating. There are different definitions of an activity that is an important component of constructivism and mentioned mostly in mathematics curricula.

Research on how activity is defined by students, teachers and pre-service teachers show that there are various definitions and there isn't a common approach on this topic. There are also research investigating the effects of activity based teaching on success and attitude in the related literature (Batd1, 2014; Gürbüz, 2010; Küpcü, 2012). According to the results of these studies, activity based teaching supports success in higher degree. Moreover, students comprehend the concepts better in activity based courses then classical methods based courses.

The study is designed as a phenomenology to determine pre-service teachers' (PST) perceptions of mathematical activity. The study group consists of 47 junior and senior PST attending primary education and 21 junior and senior PST attending elementary mathematics education department of a university in Ankara. The data is collected by having the PST fill two forms. In the first form, PST were asked to complete the sentence "the first thing in my mind when the term of activity is considered is ..." regarding mathematics teaching. After completing this form they were asked to answer the following questions in the second form:

1. How do you define the term "activity"?

2. What are the components of an activity?

3. What is the role of a student in an activity?

4. What is the role of a teacher in an activity?

5. What are the qualifications of a good activity?

Content analysis method was applied to analyze the data. All data was coded by two researchers and then those coded data were compared and the themes were determined for each question.

The categories were emerged by the answers of PST of two departments when they completed the sentence of "the first thing in my mind when the term of activity is considered is ..." regarding mathematics teaching. These categories are "aim", "qualification" and "labeling". PST perceive the aim of an activity as enforcing, teaching, reification and meaningful learning. PST completed the given sentence with relaxing, didactic, joyful, appropriate for the level of the students, efficient and visual that they should be considered in the qualification category. For the labeling the category the sentence is completed with study, sample, drill, individual and group work, applications, material and concrete data.

PST' definitions of an activity could be examined in three categories similar to their completion of the sentence of "the first thing in my mind when the term of activity is considered is ...". In the aim category, to learn and comprehend the subject, to reinforce, to provide students to be active and think differently, to reify, to make the lesson effective and improve skills are the aims of an activity mentioned by the PST. Being relaxing, deductive, pleasurable, appropriate for the 
Kurt Erhan, G., Yiğitcan Nayir, Ö. (2017). Etkinlik kavramının öğretmen adaylarının bakış açısıyla farklı boyutlarda incelenmesi. International Journal of Social Sciences and Education Research, 3(1), 283-296.

student level, productive, visual, supporting mental development, student centered and interesting are the qualifications of an activity that PST mentioned in the qualification category. Practice, movement, sample and drill, individual and group work, applications, material and all the concrete data are codes of the labeling category which identifies an activity from PST' perspective.

PST' answers to the question of what are the components of an activity are classified as four categories. Student, teacher, environment and peer are the codes of the basic components category. Pre-service primary teachers mention mostly the codes of the written documents category. Subject, objective, plan, students' level, aim and the time are the codes of this category. Material is the mostly used component by the participants in the process-product category. Perception, reinforcement, students' readiness and communication are the codes of the category of affective.

The most frequent mentioned role of a student in an activity is being active. Being willing, center of the activity, curious, responsible and to carry out the activity are other roles of a student in an activity mentioned by the PST of both departments. PST' answers to the question of what is the role of a teacher in an activity could be examined in two categories: Student-intended roles and individual roles. To be a mentor, to take into consideration the students' needs are the mostly mentioned roles of this category. Being empathetic, equitable and care about students' ideas, being concerned, a good observer are the other roles considered in the individual roles category.

Mostly given answers of the question of what are the qualifications of a good activity are to be appropriate for the level of the students, related to the subject, remarkable, clear, deductive, and planned. It is necessary to put forward a common definition of an activity to understand this concept. Classroom discussions should be allowed to learn about PST' perceptions of the activity. Gathering all the ideas on the qualifications of a good activity and roles of students and teachers in an activity would enable to construct the conceptual basis of the concept. After this process, whether their activities include the supposed components and qualifications could be investigated. Moreover, their practice could be observed. 